\title{
Learning number sense through digital games with intrinsic feedback
}

Diana Laurillard

University College London

\begin{abstract}
The paper proposes a new interdisciplinary approach to helping low attaining learners in basic mathematics. It reports on the research-informed design and user testing of an adaptive digital game based on constructionist tasks with intrinsic feedback. The approach uses findings from the neuroscience of dyscalculia, cognitive science research on conceptual understanding in mathematics, and mathematical education research to inform the detailed pedagogic design. It is interdisciplinary in the sense that it synthesises the results from multiple disciplines in the design principles. It then exploits the new capabilities of digital technologies to develop the design for testing with learners, and capturing appropriate data. The initial pilot has shown that the game supports learners age 5-7 years for independent learning of the kind that low attaining learners will need in order to keep pace with mainstream learners. The experimental work will evaluate this and similar games for learners of all ages who have low numeracy. In general, the approach is to (i) focus on a problem at the intersection of robust evidence in both education and neursocience; and (ii) use this data to design and test a digital intervention that fully exploits the adaptive and interactive features of learning technology.
\end{abstract}

\section{Introduction}

This paper proposes a way of using what we know from the learning sciences of neuroscience, cognitive science, and pedagogy to develop a theory-driven approach to designing a digital environment for learning. As learners use digital environments they leave digital traces of their activities, a capability that creates a significant new methodological tool for improving the learning of, for example, mathematical concepts.

The neuroscience can help us understand the nature of certain types of conceptual difficulty. Cognitive science demonstrates the behavioural correlates of conceptual understanding. Pedagogic theory tells us what learners need to do to build formal conceptual understanding. A good way to test how these disciplines can have an impact on learning is to bring them together to address the toughest challenges for education. Developing conceptual understanding is a challenge in every discipline, throughout every stage of formal education, from early learning to higher and professional education. One significant challenge is in mathematics education, because of its prevalence: across the Organisation for Economic Co-operation and Development (OECD) countries, for example, 23\% of 15 year olds are below Level 2, the baseline level of proficiency in mathematics (Organisation for Economic Co-operation and Development [OECD], 2014).

There are many possible reasons for this, and certainly one contributing factor is the insufficient recognition of cognitive difficulties. The $23 \%$ includes the $3-6 \%$ of learners who have developmental dyscalculia, a developmental neural deficit, also defined as a lack of number sense (Szucs, Devine, Soltesz, Nobes, \& Gabriel, 2013). For them the concept of number remains a problem throughout life. It affects the courses they can study, and the professions they are allowed to enter (such as teaching) that require basic maths. Some enlightened universities offer special dispensation for students with dyscalculia, as for the more widely recognised condition of dyslexia, but not many. They would be lucky to get there, in any case. Some public schools in the UK refuse to take such students, and few schools have the capacity to give the extra tuition they need. The problem of remediating dyscalculia and low numeracy is therefore critical for millions of learners. A successful intervention would be of value to the millions of adults for whom maths remains a challenge, in many walks of life.

If we could use educational neuroscience to develop theory-informed interventions to help the most mathematically challenged learners, that would certainly also benefit those who fail in maths for other 
reasons. Dyscalculia is a tractable research problem for educational neuroscience, because it is at the intersection of a valuable corpus of studies in both neuroscience and cognitive science that could now inform a digital pedagogic design.

The paper begins with a review of the ways in which neuroscience, cognitive science, and mathematics education studies have sought an understanding of poor performance in mathematics, and the forms of intervention they have investigated. Interventions based on the different research literatures take many forms, from major curriculum developments that include digital activities (Clements, 2007) to specific digital games (Wilson, Dehaene, et al., 2006). They set out to demonstrate the efficacy of the design through improvements in student performance. The interactive nature of digital environments is used to provide practice with either extrinsic feedback - an evaluation of the learner input, or intrinsic feedback information about the result of the input (Butterworth \& Laurillard, 2010).

This paper considers the additional value a digital environment could contribute to curriculum resources by modelling the more constructionist approach of special needs teachers who work with adults and children with low numeracy. The combination of the personalised adaptivity and intrinsic feedback that is unique to digital environments may have the potential to meet the challenge of a learning disability like dyscalculia. The implications of this interdisciplinary methodology are central to the concerns of this special issue. Bringing neuroscience, cognitive science, and education together to work on addressing the toughest challenges for education enables us to focus on how each discipline can make use of the other.

\section{Educational implications of the cognitive neuroscience of dyscalculia}

Developmental dyscalculia (DD) is a arithmetical disorder, with an estimated prevalence of 3-7\% (Shalev, 2007). Moreover, there is evidence that up to $20 \%$ of individuals of all ages have some form of mathematical learning disability (Iuculano et al., 2015), which makes learning basic mathematical numeracy a significant educational challenge.

\section{Dyscalculia and number sense}

Dyscalculia is distinct from low numeracy, which can occur for many reasons, such as lack of opportunity, inappropriate teaching, lack of numerical activities in the home, or other cognitive disabilities. It is described as a core deficit in number sense, i.e. a reduced understanding of the meaning of numbers, and low performance on non-symbolic tasks such as comparison, estimation, or approximate addition of dot arrays, and on symbolic tasks such as numerical comparison and approximation (Wilson, Revkin, Cohen, Cohen, \& Dehaene, 2006). Slow and inaccurate dot enumeration in kindergarten is a reliable predictor of the poor arithmetical attainment up to at least the age of 11 years (Reeve, Reynolds, Humberstone, \& Butterworth, 2012). It is possible to use this simple measure to make an early identification of children likely to present with dyscalculia.

The dyscalculia screener (http://www.gl-assessment.co.uk/products/dyscalculia-screener) therefore tests number sense capacity (for dot enumeration and number comparison), and arithmetical attainment (addition and multiplication), where the former depend very little on teaching, and the latter demonstrates successful teaching (Butterworth, 2003). An individual with scores that are typical on the capacity tasks would not be considered dyscalculic, but as needing more or better teaching.

In an attempt to give the reader an experiential sense of being dyscalculic, it may help to know that such learners have no difficulty in counting; the problem is that they see it simply as an arbitrary, ordered sequence, rather like the alphabet. They use counting to solve every problem. For example, a dyscalculic 9-year-old asked to count backwards in ones from 10, counted up from 1 to 9, and announced "9", then counted up from 1 to 8 and announced "8", and so on. Many of us, asked to recite the alphabet backwards from Q, say, would adopt a similar strategy, because it is simply an ordered sequence with no meaningful structural relationship between the terms. Similarly, asked what is the relation between 9 and 13 we could come up with something, while being asked what is the relation between Q and Y, we would probably find it hard to understand the question. Dyscalculia seems to turn the natural numbers into an arbitrary sequence with no internal structure. 
This is significant because the awareness of mathematical pattern and structure, such as a domino or dice patterns, clock faces, or grids, is strongly associated with the conceptual understanding of mathematics (Mulligan \& Mitchelmore, 2009). The conception of number as having an internal structure is developed during childhood, and is foundational for enumeration (Starkey \& McCandliss, 2014). Learners who can use groupitising (using grouping cues to see smaller numerical structures within a dot array) have faster reaction times on enumeration tasks, but pre-school children exhibit no such advantage because the perception of structure "emerges and develops over early elementary school as children's conceptual knowledge of numbers is being progressively enhanced” (Starkey \& McCandliss, 2014; p. 133). Dyscalculic learners are those for whom it seems the structural properties of numbers do not emerge, and they therefore do not see the internal structures that enable groupitising for efficient enumeration, a problem that persists through to adulthood if not remediated. This may be because visuo-spatial memory is impaired for DDs, which means that their transformations and operations such as adding and subtracting, which can be imagined in relation to a number line, lack this useful scaffolding (Szucs et al., 2013). Szucs et al. (2013) conclude that theories other than magnitude representation, which derive from behavioural research, should now be considered. In this paper the focus is on the structural properties of number.

\section{The consequences for learners}

Dyscalculia is a developmental disorder, and is often not recognised, and even less often addressed with specialist teaching. It is prevalent in adults as well as children, leading to the same kinds of lifelong effects of exclusion found for dyslexia (Parsons \& Bynner, 2005). Several studies have shown that children and adults with normal IQ and working memory can also have very low numerical abilities (Halberda, Mazzocco, \& Feigenson, 2008; Landerl, Bevan, \& Butterworth, 2004), and dyscalculia has been identified in high functioning adults such as businessmen, CEOs, top journalists, etc. It is most important, therefore, that anyone with the disability knows it is a disability, and not a property of their intelligence. Cognitive studies of learners with dyscalculia show that although it often co-occurs with disabilities such as dyslexia and dyspraxia, it can also occur in learners with no other disability (Butterworth, 2005; Butterworth, 2010).

Research in cognitive and developmental neuroscience is helping us to understand the cognitive implications for learners of being dyscalculic. For example:

a) DDs show reduced activation in the intraparietal sulcus (IPS), which is where typically developing learners process tasks such as comparing numerosities (Mussolin et al., 2009, Price, Holloway, Räsänen, Vesterinen, \& Ansari, 2007), comparing number symbols (Mussolin et al., 2009), and arithmetic (Kucian et al., 2006). This means that DD learners have not been able to automate this kind of processing, and must continue to use the frontal lobes, which are needed for tasks that the individual currently finds very complex, such as the early stages of arithmetic.

b) DDs show differences in connectivity among the relevant parietal regions, and between these parietal regions and occipito-temporal regions associated with processing symbolic number form (Rykhlevskaia, Uddin, Kondos, \& Menon, 2009), in comparison with typically developing learners. This means that DD learners have not sufficiently developed the structural connections between brain regions that coordinate the components needed for calculation (Price \& Ansari, 2012; Tsang, Dougherty, Deutsch, Wandell, \& Ben-Shachar, 2009).

In this way the neuroscience identifies the nature of the conceptual gap that DD learners must bridge: to be able to process basic number tasks automatically as the foundation for more complex arithmetic. It explains why these learners need to do a great deal of processing of a kind that will of atypical experience of active cognitive construction and develop the appropriate connectivity (Price \& Ansari, 2012). This does not specify directly what teachers and learners must do, but the implications of these findings for the pedagogical content knowledge about teaching number concepts to DDs are, respectively, that:

a) DD learners need much more time than mainstream learners to achieve the same level of numerical capability; and

b) they need much more practice than mainstream learners in processing and manipulating sets of objects, interpreting the relationships between sets and digits, and carrying out manipulations of objects, and of mathematical digits and symbols. 
Special needs teachers know this, and use a wide variety of manipulation activities in their classes (Emerson \& Babtie, 2014; Yeo, 2003), helping dyscalculics learn about the meaning of numbers by using concrete materials, and by articulating their practice in multiple representations of diagrams and number lines, and then building up to symbols and equations (Emerson \& Babtie, 2014). Early maths education for mainstream learners often uses the same pedagogical methods, but DDs need much more time on task to embed the concepts.

Unfortunately, in many schools in many countries, even if they recognise dyscalculia as a developmental disorder, there are too few specialist teachers to provide one-to-one support, and the lessons are too infrequent for learners to retain new skills and concepts until the next lesson. It is very difficult, therefore, for a learner with this problem to progress far in the numerical aspects of mathematics. Without a basic maths qualification some areas of employment and further study are closed to them. Some universities make provision for students who are dyscalculic, as they do for those with dyslexia, but this is still rare, and the problem has life-changing effects. It is impossible to become a teacher, for example, without a basic maths qualification.

The consequences for learners when universities do not recognise dyscalculia are life-changing, therefore. While those with the better understood condition of dyslexia are given more time in critical exams, those with dyscalculia are often excluded from courses in which they might have excelled, and may be excluded also from their chosen profession.

\section{Teaching for conceptual understanding}

Given the complexity of the curriculum, the mathematical education literature identifies number sense with a much wider range of concepts and skills than the cognitive neuroscience recognises, offering as many as 30 alleged components of number sense (Berch, 2005). These include work with estimation, magnitude comparisons, and forms of representation, and structural components such as the ability to decompose numbers, number meanings, and number patterns.

The teaching of number sense leading to basic arithmetic skills has been studied widely in mathematics education as part of the effort to develop research-informed curricula and instructional materials (Clements, 2007). Instructional materials are based on studies in cognitive science that measure and correlate mathematical behaviours with mathematical performance, for different kinds of concept and skill. The pedagogic design is to give learners practice in the behaviours identified with better performance, as in the Building Blocks curriculum (Sarama \& Clements, 2004), which uses digital games for practice with addition, subtraction, place value, etc., along with classroom teaching. The software is broadly instructionist. One activity, for example, focuses on what research indicates is a foundational cognitive building block of addition:

Mentally combining two groups into one larger group-even before knowing the specific number. The context is a shop. A customer orders two types of items, and the task is to label these two collections in two separate boxes. The customer asks for one box and the learner moves all the objects into one new box and must label the new box with the sum. Extrinsic feedback tells them if they are right or wrong (Sarama, \& Clements 2004).

These are tasks that appear to give mainstream learners opportunities to notice patterns and structures. However, the dyscalculic learner would solve such a problem by counting, because the task does not require mentally combining two groups into a larger group. They can as easily combine the groups and then count them. The aim of the current project is to make a difference to the learners who are struggling most. This means using the findings from cognitive and neuroscience research on dyscalculia to design a different pedagogy, that is to require the actions that help DDs develop a fundamental sense of the internal structure of numbers, which for them does not seem to emerge.

\section{A constructionist approach to formal conceptual learning}

The neuroscience findings do not fully determine the pedagogical content knowledge needed to devise a solution for a dyscalculic learner. We know they need more time and manipulative practice with objects, 
and not just with number line representations. The question is: What kinds of tasks should the learner be doing?

From Dewey onwards, learning and instructional theorists, no matter what their discipline focus, have been unanimous in emphasising the importance of learning through experience (Bruner, 1961; Dewey, 1938; Kolb, Boyatzis, \& Mainemelis, 2000), learning through practice (Romiszowski, 1999; Senge, 2006), learning by doing (Schank, Berman, \& Macpherson, 1999; Schön, 1987), learning by constructing (Kafai \& Resnik, 1996; Papert \& Harel, 1991), or situated learning (Brown, Collins, \& Duguid, 1989; Lave \& Wenger, 1991). Mathematics teaching has always taken this advice to heart, and has offered plenty of practice through classes, textbooks, tutorials, and now educational apps. But practice takes many forms, and is not necessarily the route to conceptual understanding in itself. We have to consider what it takes to learn each mathematical concept in order to design an appropriate form of practice.

Special needs teachers spend a great deal of time with manipulables, to build learners' conceptual awareness of numbers as combinations of other numbers (Butterworth \& Yeo, 2004). This type of learning through manipulation is close to what Seymour Papert described as learning through a constructionist approach, such as that afforded by a microworld - a digital environment designed to afford the learning of some system or set of concepts and powerful ideas (Healy \& Kynigos, 2010; Noss \& Hoyles, 2006; Papert, 1980). The original example was to learn about geometrical concepts such as triangles in a microworld in which learners test the commands that would make a robot turtle draw a triangle, using only the terms and parameters "go forward $n$ steps", "turn through $x$ degrees", "stop”. The pedagogic value is that by aiming to achieve a goal they understand, the learner can interpret the result of their action (the shape the robot draws) in relation to the intended goal, and can experiment to repair any mistake in their commands without being told they are wrong, or how to correct their initial action. The term microworld is apposite because it models a little world that affords the learning of a concept, "a place where the student, through playing, may stumble over and then ponder important inspirations and concepts” (Hoyles, Noss, \& Adamson, 2002; p. 29). The construction may take the form of programming the objects, as in turtle geometry, or manipulating the designer's model of mathematical object behaviour (Edwards, 1998), which is the sense in which it is used here.

The central claim of constructionism is that if the learning is situated in a meaningful context with a meaningful goal in view, the learner can use just the direct feedback from the environment to improve their actions, without needing further external advice or guidance. This type of feedback is intrinsic to the action, representing the consequence of the action in relation to the intended goal, from which the learner can work out how to improve their action without extrinsic teacher intervention (Laurillard, 2012). The contrast is with apps such as those in the National Library of Virtual Manipulatives in the United States of America (nlvm.usu.edu/en/nav/category_g_1_t_1.html), which are used along with concrete manipulatives, as well as teacher guidance (Hunt, Nipper, \& Nash, 2011). In some activities there is no goal, and the consequences of learners' actions therefore represent no opportunity for challenge and do not require the learner to work out what to do next. Another study used digital games to require use of the component abilities for number sense: the learner has to construct their answer, for example to place the number of fingers on the screen that represent the total of two strawberries and three pears (Baccaglini-Frank \& Maracci, 2015). However, the feedback is extrinsic as they have to be told if it is right or wrong, with no means to make the judgment themselves, and therefore there is no requirement to develop their concept. The opportunity is there, but a learner who does not see the patterns and structures, and relies on counting, will not be able to progress.

The intrinsic versus extrinsic distinction has been identified also as consequences of actions versus coach (Schank et al., 1999), and knowledge of results versus knowledge of performance as commented on by an instructor (Romiszowski, 1999). It is similar to the neuroscience accounts of constructivist models of learning (Thomas \& Laurillard, 2012), and those where a critic element of the learning mechanism uses information from the results of the previous actions generated. Again, the learning environment supplies intrinsic feedback on the actions, not guidance from an external element such as a coach or supervisor (Dayan \& Abbott, 2001; Thomas \& Laurillard, 2012). To recruit these natural learning mechanisms to mathematical reasoning means designing constructionist learning activities that promote and require them. 


\section{Design principles for a constructionist digital game}

The aim of our project, therefore, was to test whether a constructionist microworld could be designed for manipulating sets of objects and their numbers, which would:

a) enable a dyscalculic learner to build the foundational conceptual understanding of numbers as combinations of other numbers, and

b) provide support for independent learning beyond the classroom, enabling them to spend the time they need on this development.

Any digital learning environment that can be run on a personal device enables the learner to practice in their own time at their own pace, and provides immediate feedback according to its algorithm or model. These are the features that have led to the creation of hundreds, probably thousands, of educational apps for learning arithmetic, intended to support the weaker learners. However, the great majority of educational apps for maths have very simple algorithms, and features that do not foster conceptual learning:

- the task is to answer a multiple choice question, which (a) motivates guessing, and (b) invites learners to think about wrong answers;

- goals and feedback are extrinsic to the actions so do not develop the concept;

- the tasks are randomly generated and are not adaptive to the learner's current performance and needs (Baajour \& Laurillard, 2009);

- they have graphics, animations, sounds, and storylines, that have no intrinsic integration with the conceptual content, and are simply distracting (Habgood \& Ainsworth, 2011).

The alternative proposed here is to design a constructionist app with contrasting features that aim to foster conceptual learning:

- the task is to construct an action to achieve a goal;

- the goal is interpretable by the learner;

- the action is within their repertoire of possible actions;

- the feedback is a representation of the results of that action in relation to the goal, so it is intrinsic to the action;

- the pace and difficulty level adapts to the learner's performance.

Papert's turtle robot had all these benefits of a digital environment, where the learning is self-paced, selfcorrected with immediate feedback, and adaptive.

\section{Task design}

For learning about the structural form and relationships of numbers, we designed a similarly constructionist game, with those same features. The game NumberBeads generates a play area with sets of colour-coded beads of different numerosities. The goal is a specific set, displayed at the top, and the task is to construct the target set from the sets available, and if they make a non-match to deduce the next action to construct a set that matches (see Figure 1). 
(a)

(c)

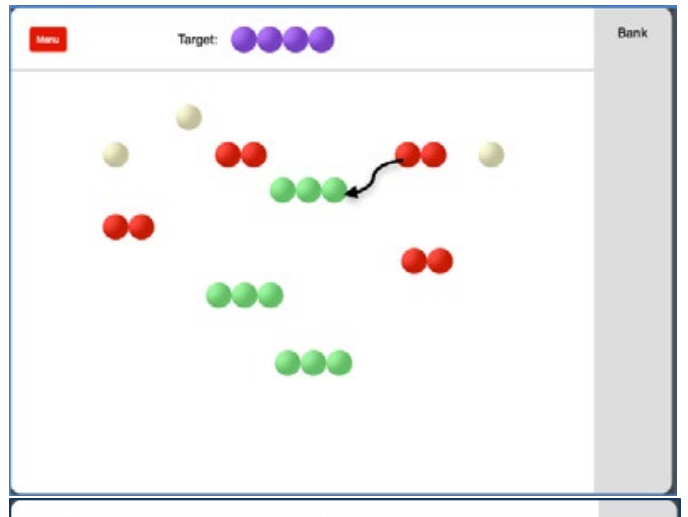

(b)

(d)

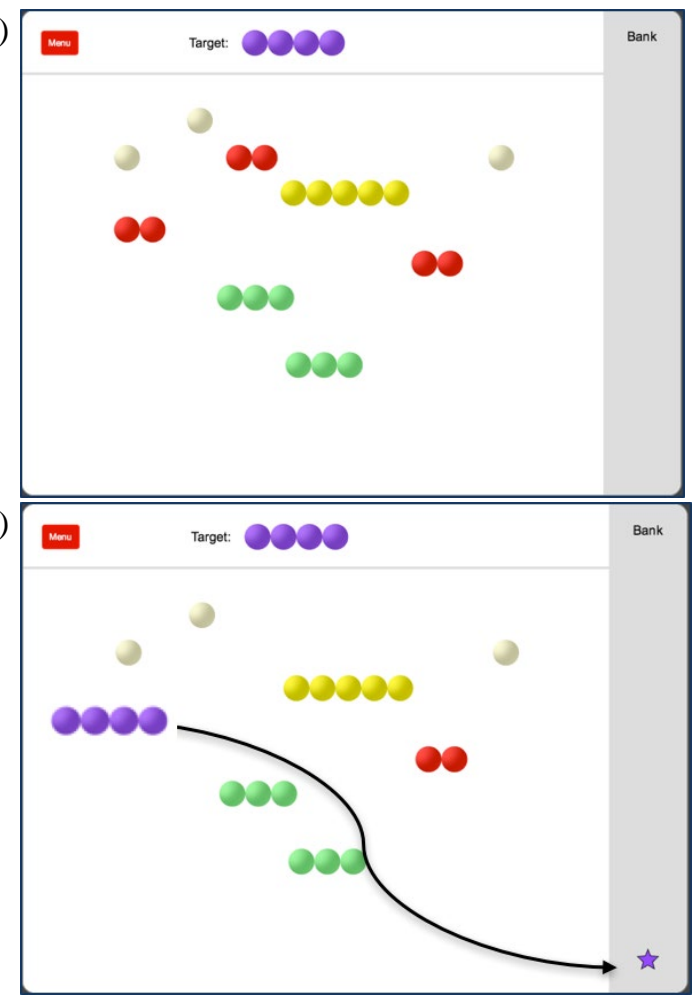

Figure 1. A sequence of learner moves to achieve the target set.

In Figure 1, the target set is shown at the top, colour coded for each number up to 10. The learner constructs the target by either moving a set next to another to combine them, or by splitting a set (a cutting action). The screenshots in Figure 1 show the sequence of actions: (a) the start condition of the play area, where an arrow shows the user's first move; (b) moving 2 red beads to join 3 green beads has made 5 yellow beads, a non-match; (c) the user moves 2 red beads to join 2 red beads; and (d) this makes 4 purple beads, the target, which then turns into a star and moves to the Bank.

At this point the action of splitting (drawing a finger or the mouse through the 5 beads) could turn the yellow 5 set into a white 1 and a purple 4 to make the target. As the bead sets are used up, more are spawned onto the play area, until the user has the threshold number of stars in the Bank, as determined by the adaptive algorithm and their current performance.

Once the learner has collected enough successful matches in the Bank, the game generates a new task where the target is the next number up to 10 . Once all numbers to 10 are done, the game generates format 2, (digits are attached to each set), format 3 , (colour coding is removed), and format 4 (beads are removed to leave only digits to play with), see Figure 2.
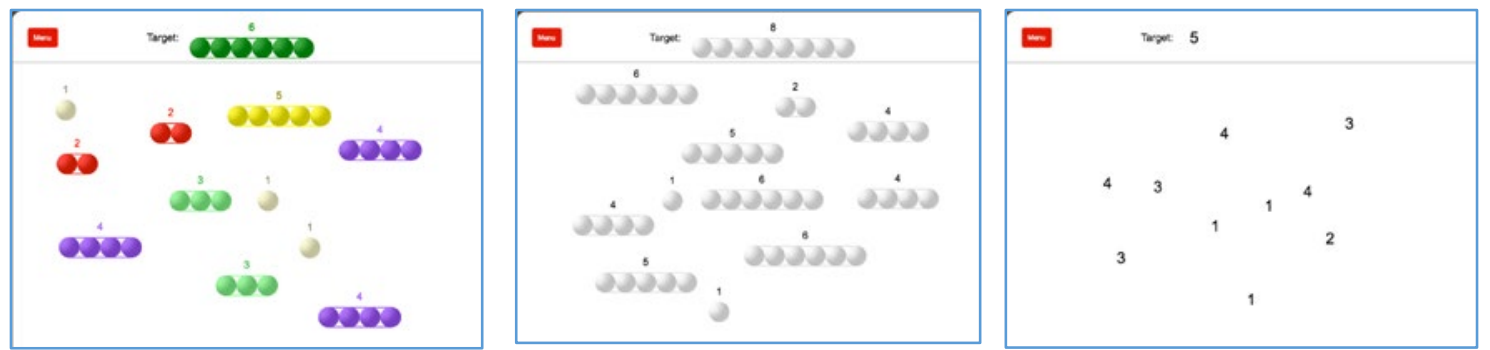

Figure 2. The successive formats 2, 3, and 4 of the game, scaffolding the progression to the manipulation of digits only. 
The successive formats scaffold the learner's progression from working with the length, numerosity and colour of a set in format 1 , to associating digits with length, numerosity, and colour, then with just length and numerosity, until at the end they are working with just digits.

(a)

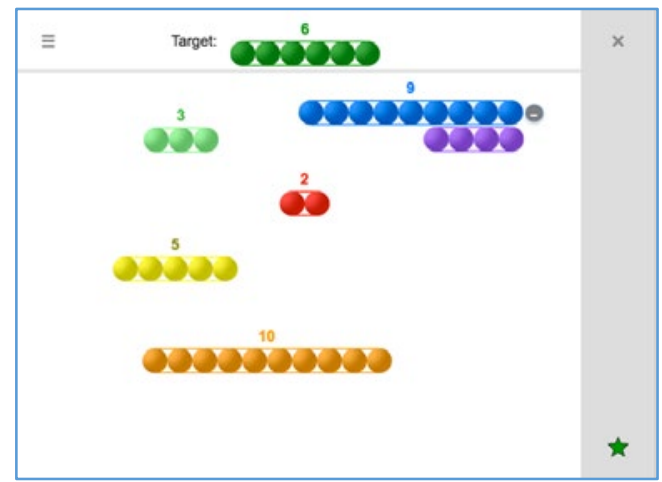

(b)

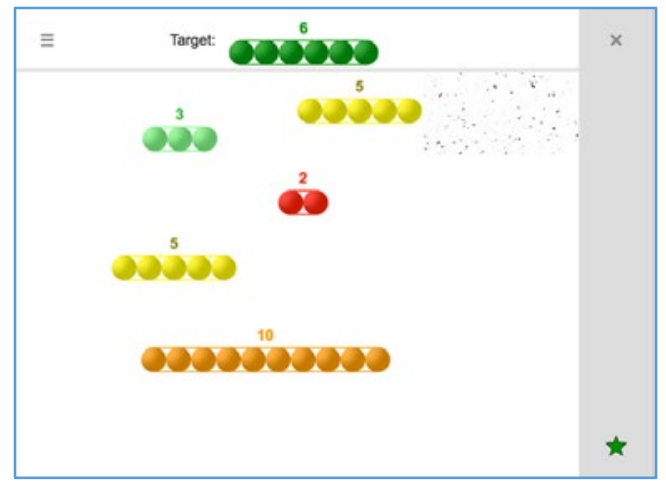

Figure 3. The subtraction action to take 4 from 9.

In the latter stages of the game the splitting action is disabled and the subtraction action is demonstrated to show that, as in Figure 3a, as you bring a set beneath a larger set a minus sign appears, and on releasing the mouse or finger, as in Figure 3b, the smaller set dissolves that amount of the larger set to leave the remainder set. In this way it represents the cancelling out of one number by another: $4-4$ is nothing, so the two sets dissolve to nothing, leaving the 5 set as the remainder. The spawning action is programmed to produce the small and large sets that make it easy to use subtraction to produce the target - as is now needed for the state in Figure 3b.

By the latter stages, therefore, the learner is working with just digits and symbols, where the target is a digit, and as they manipulate the digits in the play area the symbols "+" and "-” are generated to link the digits according to whether the learner's action is adding or subtracting. Throughout all the stages the learner is composing and decomposing numbers to make a target number in a series of different representational formats. The behaviour of the objects in the microworld remains faithful to the learner's intention, no matter what the goal, and never says they are wrong, but only shows them what they have made in relation to the target.

The specific properties of such a digital environment improve on the physical manipulation of objects (Butterworth \& Laurillard, 2010), for example: by using virtual objects to emulate abstract ideas, e.g. 2 reds and 3 greens turning into 5 yellows; providing endless examples; going at the pace of the learner; providing support with privacy; and where no one else knows the mistakes you make. The latter point is very important, for younger and older learners alike, as the separation by ability into special groups can generate a stigma associated with learning maths that is never healed.

\section{Adaptive algorithms}

The digital environment can also model the way a teacher scaffolds the learner's development by adapting the next task to their current likely level of performance. The successive formats described above are designed to do this. Learners work through each round (a sequence of tasks to make a number from 3 to 10 within each format) taking as many actions as they need to reach the required number of successful actions. It is possible for the learner to use a menu to move to a more advanced level if they wish, although this facility could be disabled in the teacher's configuration of the game.

The adaptive algorithms select the next task using the following rules, where a round is the sequence of $N$ tasks to make the current target set:

a) The required number of successful actions, $N$, for a round increases by 1 for each successive round. The starting condition $N$ is a designer preference.

b) The current accuracy is defined in terms of the number correct and percentage correct in the current format. The required accuracy is a designer preference, where the default requires greater than $50 \%$ correct. A round is complete for accuracy when current accuracy equals required accuracy. 
c) The current fluency is defined in terms of the average time taken to complete successful actions. The required fluency is a designer preference. A round is complete for fluency when current fluency equals required fluency.

d) A round is complete when both accuracy and fluency conditions are met, and the next task uses the next number as the target set within that format or, if the format is complete, in the next format.

e) If a round is not complete within $N$ actions, then the learner is invited to repeat it or return to an earlier format. The parameter $N$ is a designer preference.

Designer preferences are enabled by the researcher for a teacher to change. This is important because some learners may be slow for reasons other than mathematical ability. For experiments, teacher preferences are disabled.

\section{The methodological approach}

The empirical testing of games of this type has shown that, (a) learners can achieve much more practice in a given period than is possible in a taught class, (b) performance improves within a lesson period, and (c) special needs teacher evaluations are high (Butterworth, Varma, \& Laurillard, 2011).

\section{The experimental design}

The NumberBeads game will be tested against a control game that uses the same representations of sets but in a multiple-choice format, with no adaptivity to performance, emulating the majority of current educational maths games. Both game designs will be tested using pre- and post-tests of performance on standard arithmetic manipulations of the form $\mathrm{A}+\mathrm{B}=$ ?, $\mathrm{A}+$ ? $=\mathrm{B}, \mathrm{A}-\mathrm{B}=$ ?, $\mathrm{A}-$ ? = B, to test knowledge of the addition, subtraction, and the commutativity and inverse principles of arithmetic. They are embedded as part of each game and can be set in designer preferences to run before and after every session, or on a weekly basis, or over a longer period, according to the experiment being run.

The experimental aim is to test the games with dyscalculic learners in all age groups. The hypotheses are that, for all age groups:

1. NumberBeads yields a small improvement for mainstream learners, and a larger improvement for DDs.

2. NumberBeads leads to larger improvements than the control game for both groups.

3. There is some structural change in the IPS that correlates with behavioural learning.

4. DDs take more trials to achieve any shift to the IPS than mainstream learners.

Both the games will collect the behavioural data for conceptual progress defined in terms of each learner's speed and accuracy at each level, and the transfer of learning to numbers and then to arithmetic. The neural markers for the type of processing being used will be tested through EEG before and after each game has been used over a period of time. Comparisons of behaviour recorded in the digital traces will be carried out for individuals' progress over time, dyscalculic vs typically developing learners, the constructionist vs multiple choice versions, and for different age groups. Some individuals will also be tracked over a longer period, to check whether any long-term changes in behavior and neural processing can be detected.

\section{Current findings}

The early trials of the game were with primary school pupils aged 5-8 years in a special needs group, all of whom are teacher-assessed as weak in arithmetic. Responses show that they greatly enjoy playing it, and are keen to continue: "It's very fun”, “It's a really fun game”, “This is a really fun game - I don't want anyone to know about it”, “This game is the best”, "Really fun”, “It’s cool - I love this”, "I’d play it all day”.

This is important for their continued and repeated unsupervised practice. If they can be motivated to generate many hundreds of numerical transactions in the course of playing the game, then there is some chance that their behavior, cognition and neural processing will change for the long term. Research is still at the early stage so there is no formal experimental data. Comments from their very experienced special 
needs teacher suggest that the learning experience is quite different from what they could normally do in class:

I've been absolutely staggered today to see how quickly these children have been able to manipulate the game ... the Year 2, 3, 4 children, the ones I know well, who have great difficulty adding quickly, seeing the combinations of things, I was absolutely astounded at the work they were doing with this. They were clearly seeing things in a different way ... we were seeing here some of the ones who are having the most trouble.

The game was also piloted with children whose parents thought they were having some difficulties with arithmetic at school. The program runs online so all data is collected automatically. The 12 children, with ages ranging from 4 to 10 years, used it in the lab for 15-20 minutes, with no teacher help, and were then able to use it voluntarily at home online. Tracking their use of the game showed that some children continued and improved their performance unsupervised at home. This personalised independent learning is important for increasing time on task for slower learners. A Grade 1 learner used it for 14 minutes in the lab, and did 45 actions, at 18 second per action, on average. At home she did a further 18 minutes, and did 145 task actions, at 7 seconds per action to complete the first two formats altogether. Previous studies have shown that the time on task in terms of computer-supported transactions within a 20-minute period on games of this type is far greater than activities typical of a small special educational needs (SEN) group (Butterworth \& Laurillard, 2010).

A Grade 4 learner diagnosed as dyscalculic chose to repeat the first three numbers in format 1 and was able to maintain a reasonable level of accuracy (Figure 4).

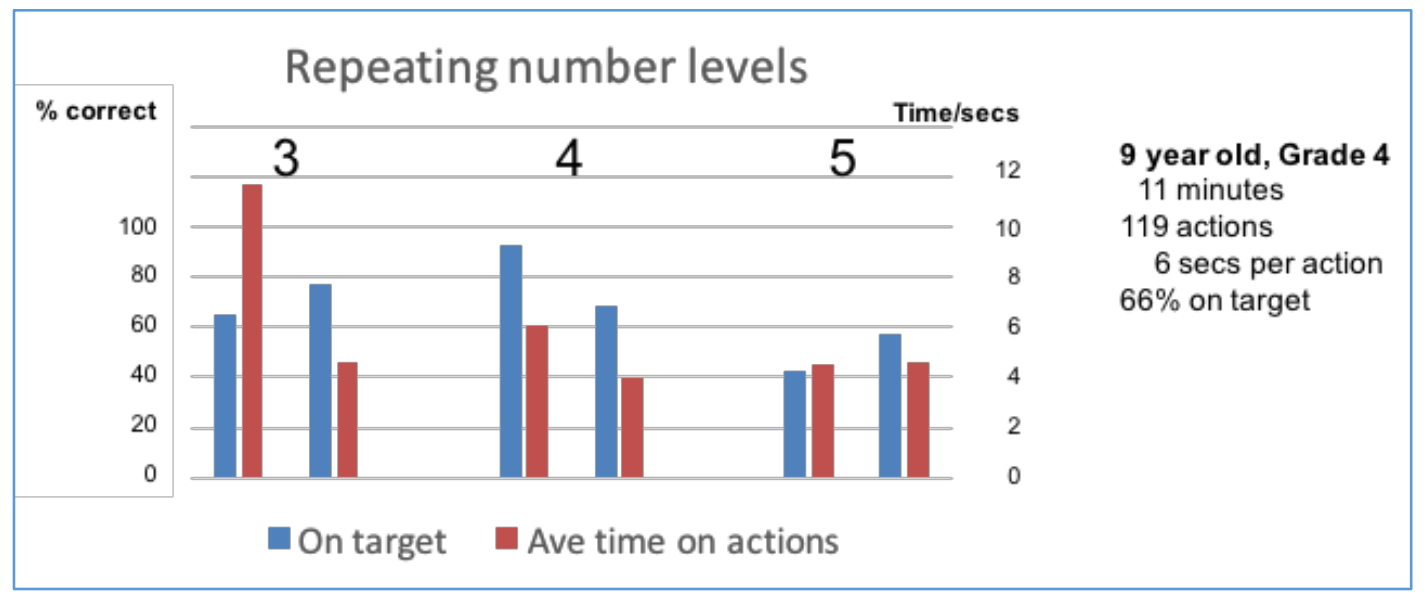

Figure 4. A dyscalculic child chooses to repeat each number and can reduce their average time per action while maintaining a reasonable level of accuracy.

This intensive computer-supported practice on very large numbers of number-processing tasks across all levels of the game (which takes over an hour for a competent adult) may be sufficient to do what Price and Ansari (2012) argue is needed to counter the many years of atypical experience of active cognitive construction for DDs. The next phase of experimentation will put this hypothesis to the test.

\section{Conclusion}

The aim of this paper is to give an account of an iterative interdisciplinary approach to learning. It is illustrated by using the findings from neuroscience and cognitive science to inform a pedagogical design for a digital environment targeted on the structural aspects of number for the specific learning difficulty of dyscalculia, which affects learners of all ages.

The paper has clarified the nature of the constructionist approach, and its application to the design of conceptual learning activities in a digital environment. Early tests of the software with target learners are encouraging, and results of the comparative studies will be reported in the near future. The pilot study also suggests that these adaptive constructionist digital games can support independent learning, which is 
important for many types of special needs where learners need more time and more active learning than is needed by mainstream learners. It would be especially valuable for older secondary school and adult learners who continue to struggle with basic numeracy, as it would supplement the very sparse support these learners have beyond primary school.

The paper has noted the evidence that up to $20 \%$ of individuals of all ages have some form of mathematical learning disability, and the comparable OECD finding that $23 \%$ of 15 year olds are below Level 2, the baseline level of proficiency in mathematics. The failure to develop such a high proportion of the future workforce in a capability that is required for basic employability in all sectors, has a considerable impact in society, and also on higher education, because it excludes so many potential students from certain kinds of study. It is not possible to enter university without a maths qualification, for example. Without recognition and provision for learners with dyscalculia, the consequences for the individuals and for society, are a significant loss of opportunity. For those who have low numeracy for other reasons, as adults they may succeed in non-mathematical subjects by developing compensatory strategies, but will tend to avoid engaging with the use and interpretation of numerical data. This could have its own disadvantageous consequences in the workplace. A better strategy would to recognise and support these adults in their independent learning of basic maths. Perhaps a supplementary online programme of digital remediation would help to develop their instinctive understanding of number and arithmetic.

The theoretical and pedagogical design background to this study serves as an example of how we can bring neuroscience, cognitive science, and educational technology together to work on addressing the toughest challenges for education, especially for the basic skills and concepts on which higher level study depends, and to how each discipline can make use of the other.

\section{Acknowledgements}

This is to acknowledge the invaluable advice and work of Trish Babtie, who has helped with the design of the NumberBeads intervention, and by testing it with dyscalculic learners. The Science of Learning Research Centre, based at University of Queensland, Australia, funded the development of the software, undertaken by Cauldron (www.cauldron.sc). Professor Brian Butterworth helped with comments on the text and references. Professor Jason Mattingley and Associate Professor Paul Dux (Queensland Brain Institute, University of Queensland) advised on the neural methods and the design of the control game. Professor David Clarke (University of Melbourne) and Dr Mike Timms (Australian Council for Educational Research) arranged for the testing in the University of Melbourne experimental Lab. Dulcie Lay, Catherine Pearn (ACER) and Carmel Mesiti (University of Melbourne) ran the testing of learners in the Lab.

\section{References}

Baajour, H., \& Laurillard, D. (2009). Funny numbers: Using new technology to improve learning of children with dyscalculia and special needs in numeracy. Teaching Times, October 2009.

Baccaglini-Frank, A., \& Maracci, M. (2015). Multi-touch technology and preschoolers' development of number-sense. Digital Experiences in Mathematics Education, 1(1), 7-27. http://dx.doi.org/10.1007/s40751-015-0002-4

Berch, D. B. (2005). Making sense of number sense: Implications for children with mathematical disabilities. Journal of Learning Disabilities, 38(4), -339333. http://dx.doi.org/10.1177/00222194050380040901

Brown, J. S., Collins, A., \& Duguid, P. (1989). Situated cognition and the culture of learning. Educational Researcher, 18(1), 32-42. http://dx.doi.org/10.3102/0013189X018001032

Bruner, J. (1961). The act of discovery. Harvard Educational Review, 31, 21-32.

Butterworth, B. (2003). Dyscalculia Screener. London: nferNelson Publishing Company Ltd.

Butterworth, B. (2005). The development of arithmetical abilities. Journal of Child Psychology \& Psychiatry, 46(1), 3-18. http://dx.doi.org/10.1111/j.1469-7610.2004.00374.x

Butterworth, B. (2010). Foundational numerical capacities and the origins of dyscalculia. Trends in Cognitive Sciences, 14(12), 534-541. http://dx.doi.org/10.1016/j.tics.2010.09.007

Butterworth, B., \& Laurillard, D. (2010). Low numeracy and dyscalculia: Identification and intervention. ZDM Mathematics Education, Special issue on Cognitive neuroscience and mathematics learning, 42(6), 527-539. http://dx.doi.org/10.1007/s11858-010-0267-4 
Butterworth, B., Varma, S., \& Laurillard, D. (2011). Dyscalculia: From brain to education. Science, 334(6057), 761-761.. http://dx.doi.org/10.1126/science.1201536

Butterworth, B., \& Yeo, D. (2004). Dyscalculia guidance: Helping pupils with specific learning difficulties in maths. London: nferNelson Publishing Company Ltd.

Clements, D. (2007). Curriculum research: Toward a framework for "Research-based curricula". Journal for Research in Mathematics Education, 38(1), 35-70.

Dayan, P., \& Abbott, L. (2001). Classical conditioning and reinforcement learning. In P. Dayan \& L. Abbott (Eds.), Theoretical Neuroscience (pp. 331-358). Cambridge, MA: MIT Press.

Dewey, J. (1938). Experience and education. New York, NY: Kappa Delta Pi.

Edwards, L. D. (1998). Embodying mathematics and science: Microworlds as representations. Journal of Mathematical Behaviour, 17(1), 53-78. http://dx.doi.org/10.1016/S0732-3123(99)80061-3

Emerson, J., \& Babtie, P. (2014). The dyscalculia solution: Teaching number sense. London, UK: Bloomsbury Education.

Habgood, J., \& Ainsworth, S. E. (2011). Motivating children to learn effectively: Exploring the value of intrinsic integration in educational games. Journal of the Learning Sciences, 20(2), 169-206. http://dx.doi.org/10.1080/10508406.2010.508029

Halberda, J., Mazzocco, M. M. M., \& Feigenson, L. (2008). Individual differences in non-verbal number acuity correlate with maths achievement. Nature, 455(7213), 665-668. http://dx.doi.org/10.1038/nature07246

Healy, L., \& Kynigos, C. (2010). Charting the microworld territory over time: Design and construction in mathematics education. ZDM Mathematics Education, 42(1), 63-76. http://dx.doi.org/10.1007/s11858-009-0193-5

Hoyles, C., Noss, R., \& Adamson, R. (2002). Rethinking the microworld idea. Journal of Educational Computing Research, 27(1), 29-53. http://dx.doi.org/10.2190/U6X9-0M6H-MU1Q-V36X

Hunt, A. W., Nipper, K. L., \& Nash, L. E. (2011). Virtual vs. concrete manipulatives in mathematics teacher education: Is one type more effective than the other? Current Issues in Middle Level Education, 16(2), 1-6.

Iuculano, T., Rosenberg, M., Richardson, J., Tenison, C., Fuchs, L., Spupekar, K., \& Menon, V. (2015). Cognitive tutoring induces widespread neuroplasticity and remediates brain function in children with mathematical learning disabilities. Nature Communications, 6-8453. http://dx.doi.org/10.1038/ncomms9453

Kafai, Y., \& Resnik, M. (1996). Constructionism in practice: Designing, thinking and learning in a digital world. Mahwah, N.J.: Lawrence Erlbaum.

Kolb, D. A., Boyatzis, R. E., \& Mainemelis, C. (2000). Experiential learning theory: Previous research and new directions. In R. J. Sternberg \& L. F. Zhang (Eds.), Perspectives on cognitive, learning, and thinking styles. Mahwah, NJ: Lawrence Erlbaum Associates.

Kucian, K., Loenneker, T., Dietrich, T., Dosch, M., Martin, E., \& von Aster, M. (2006). Impaired neural networks for approximate calculation in dyscalculic children: a functional MRI study. Behavioral and Brain Functions, 2(31), 1-17.

Landerl, K., Bevan, A., \& Butterworth, B. (2004). Developmental dyscalculia and basic numerical capacities: A study of 8-9 year old students. Cognition, 93(2), 99-125. http://dx.doi.org/10.1016/j.cognition.2003.11.004

Laurillard, D. (2012). Teaching as a design science: Building pedagogical patterns for learning and technology. New York, NY: Routledge.

Lave, J., \& Wenger, E. (1991). Situated learning: Legitimate peripheral participation. Cambridge, MA: Cambridge University Press. http://dx.doi.org/10.1017/CBO9780511815355

Mulligan, J., \& Mitchelmore, M. (2009). Awareness of pattern and structure in early mathematical development. Mathematics Education Research Journal, 21(2), 33-49. http://dx.doi.org/10.1007/BF03217544

Mussolin, C., De Volder, A., Grandin, C., Schlögel, X., Nassogne, M.-C., \& Noël, M.-P. (2009). Neural correlates of symbolic number comparison in developmental dyscalculia. Journal of Cognitive Neuroscience, 22(5), 860-874. http://dx.doi.org/10.1162/jocn.2009.21237

Noss, R., \& Hoyles, C. (2006). Exploring mathematics through construction and collaboration. In R. K. Sawyer (Ed.), The Cambridge handbook of the learning sciences (pp. 389-405). Cambridge, MA: Cambridge University Press.

Organisation for Economic Co-operation and Development. (2014). What students know and can do: Student performance in mathematics, reading and science (Vol. I, Rev. ed. February 2014). Paris: OECD Publishing. 
Papert, S. (1980). Mindstorms: Children, computers, and powerful ideas. Brighton, Sussex: The Harvester Press.

Papert, S., \& Harel, I. (1991). Situating constructionism. In I. Harel \& S. Papert (Eds.), Constructionism: Research reports and essays, 1985-1990. (1-11). Norwood, N.J.: Ablex Pub. Corp.

Parsons, S., \& Bynner, J. (2005). Does numeracy matter more? London: National Research and Development Centre for Adult Literacy and Numeracy, Institute of Education.

Price, G., Holloway, I., Räsänen, P., Vesterinen, M., \& Ansari, D. (2007). Impaired parietal magnitude processing in developmental dyscalculia. Current Biology, 17(24), R1042-R1043. http://dx.doi.org/10.1016/j.cub.2007.10.013

Price, G., \& Ansari, D. (2012). Developmental Dyscalculia: A case for neuroscience in education. In N. Frederickson, D. Laurillard, \& A. Tolmie (Eds.), Educational Neuroscience, 8, 45-62. London: British Journal of Educational Psychology.

Reeve, R., Reynolds, F., Humberstone, J., \& Butterworth, B. (2012). Stability and change in markers of core numerical competencies. Journal of Experimental Psychology: General, 141(4), 649-666. http://dx.doi.org/10.1037/a0027520

Romiszowski, A. (1999). The development of physical skills. In C. M. Reigeluth (Ed.), Instructionaldesign theories and models: A new paradigm of instructional theory (Vol. II, pp. 457-481). Mahwah, NJ: Lawrence Erlbaum Associates.

Rykhlevskaia, E., Uddin, L. Q., Kondos, L., \& Menon, V. (2009). Neuroanatomical correlates of developmental dyscalculia: Combined evidence from morphometry and tractography. Frontiers in Human Neuroscience, 3(51), 1-13. http://dx.doi.org/10.3389/neuro.09.051.2009

Sarama, J., \& Clements, D. (2004). 'Building Blocks' for early childhood mathematics. Early Childhood Research Quarterly, 19(1), 181-189. http://dx.doi.org/10.1016/j.ecresq.2004.01.014

Schank, R. C., Berman, T. R., \& Macpherson, K. A. (1999). Learning by doing. In C. M. Reigeluth (Ed.), Instructional-design theories and models: A new paradigm of instructional theory (Vol. II, pp. 161181). Mahwah, NJ: Lawrence Erlbaum Associates. http://dx.doi.org/10.1017/cbo9780511527920.011

Schön, D. A. (1987). Educating the reflective practitioner. San Francisco, CA: Jossey-Bass.

Senge, P. (2006). The fifth discipline: The art and practice of the learning organization. Doubleday.

Shalev, R. S. (2007). Prevalence of developmental dyscalculia. In D. B. Berch \& M. M. M. Mazzocco (Eds.), Why is math so hard for some children? The nature and origins of mathematical learning difficulties and disabilities (pp. 49-60). Baltimore, MD: Paul H Brookes Publishing Co.

Starkey, G., \& McCandliss, B. (2014). The emergence of "groupitizing" in children's numerical cognition. Journal of Experimental Child Psychology, 126, 120-137. http://dx.doi.org/10.1016/j.jecp.2014.03.006

Szucs, D., Devine, A., Soltesz, F., Nobes, A., \& Gabriel, F. (2013). Developmental dyscalculia is related to visuo-spatial memory and inhibition impairment. Cortex, 49(10), 2674 - 2688. http://dx.doi.org/10.1016/j.cortex.2013.06.007

Thomas, M. S. C., \& Laurillard, D. (2012). Computational modelling of learning and teaching. In D. Mareschal, A. Tolmie, \& B. Butterworth (Eds.), Handbook of Educational Neuroscience (pp. 46-76). Oxford: Wiley-Blackwell.

Tsang, J. M., Dougherty, R. F., Deutsch, G. K., Wandell, B. A., \& Ben-Shachar, M. (2009). Frontoparietal white matter diffusion properties predict mental arithmetic skills in children. Proceedings of the National Academy of Science, 106(52), 22546-22551. http://dx.doi.org/10.1073/pnas.0906094106

Wilson, A., Dehaene, S., Pinel, P., Revkin, S., Cohen, L., \& Cohen, D. (2006). Principles underlying the design of "The Number Race", an adaptive computer game for remediation of dyscalculia. Behavioral and Brain Functions, 2(19), 1. http://dx.doi.org/10.1186/1744-9081-2-19

Wilson, A., Revkin, S., Cohen, D., Cohen, L., \& Dehaene, S. (2006). An open trial assessment of "The Number Race", an adaptive computer game for remediation of dyscalculia. Behavioral and Brain Functions, 2(20), 1. http://doi:10.1186/1744-9081-2-20

Yeo, D. (2003). A brief overview of some contemporary methodologies in primary maths. In M. Johnson \& L. Peer (Eds.), The Dyslexia Handbook. Reading: British Dyslexia Association.

Corresponding author: Diana Laurillard, d.laurillard@ucl.ac.uk

Australasian Journal of Educational Technology (c) 2016.

Please cite as: Laurillard, D. (2016). Learning number sense through digital games with intrinsic feedback. Australasian Journal of Educational Technology, 32(6), 32-44.

http://dx.doi.org/10.14742/ajet.3116 